\title{
PROGESTERONE IMPROVES PORCINE IN VITRO FERTILISATION SYSTEM
}

\author{
Clara MALO , Lydia GIL, Rafael CANO, Felisa MARTINEZ and Noelia GonZALEZ \\ Department of Animal Pathology, Obstetrics and Reproduction Area, Faculty of \\ Veterinary, Universidad de Zaragoza, Miguel Servet 177, 50013, Zaragoza, Spain
}

(Received 26 October 2012; accepted 2 April 2013)

In an effort to improve the quality of in vitro produced porcine embryos, the effect of progestagens - progesterone analogues - on the in vitro developmental competence of porcine oocytes was studied. A total of 1421 in vitro matured oocytes, from 4 replicates, were inseminated with frozen-thawed spermatozoa. Progestagens were added to late maturation and embryo cultures (10 IU/ml). Fertilisation success (pre-maturation, penetration, monospermy and efficiency) and nuclear maturation were evaluated. There were no differences among prematuration rates between groups $(\mathrm{P}=0.221)$. Penetration rates were higher $(\mathrm{P}<$ $0.001)$ in the presence of progestagens $(75.0 \%)$ as compared to the control $(51.7 \%)$. However, no differences were observed in monospermy percentages $(\mathrm{P}=0.246)$. The results indicated that supplementation with progestagens increased the efficiency of the in vitro fertilisation system $(\mathrm{P}<0.001)$. An additional beneficial effect was observed in nuclear maturation with progestagens $(\mathrm{P}=$ 0.035). In summary, progestagen supplementation is an important factor to improve the in vitro fertilisation procedure.

Key words: In vitro fertilisation, oocyte maturation, progesterone, porcine

The overall efficiency of in vitro porcine embryo production and the quality of embryos are still low when compared with in vivo results (Funahashi, 2003). One of the major problems includes improper in vitro maturation (IVM) of oocytes, in both the nuclear and cytoplasmic compartments (Niwa, 1994; Marchal et al., 2001). While a large percentage of oocytes reached metaphase II after maturation, inadequate cytoplasmic and molecular maturation occurred (Sirard et al., 2006), leading to a lack of subsequent embryo development success. There is a lack of information on ovarian factors that may be important for the maturation and subsequent fertilisation of oocytes.

The production of sex steroids by follicular cells is proposed to be influenced by the maturity of oocytes. Oestradiol, progesterone and testosterone are the main steroid hormones that play an essential role during the follicular and

*Corresponding author; E-mail: 485010@celes.unizar.es; Phone: 0034 (976) 761-544; Fax: 0034 (976) 761-612 
luteal phases of the menstrual cycle (Wen et al., 2008). Many researchers have attempted to increase in vitro penetration percentages of porcine oocytes by adding PMSG (Funahashi and Day, 1993), hCG hormone (Raziel et al., 2006) or both (Funahashi et al., 1994; Wang and Niwa, 1995; Faerge et al., 2006; Silvestre et al., 2007). However, no studies have been conducted on the effects of progesterone on in vitro fertilisation (IVF) of porcine oocytes yet. Based on in vivo observations, high concentrations of progesterone are present in porcine follicular and utero-tubal fluids (Hunter et al., 1988), but the possible actions of progesterone during early embryo development are still undetermined. Hunter (1991) hypothesised that progesterone may modify the interaction of gametes. Raychoudhury and Suárez (1991) as well as Peters and Wells (1994) affirmed that this hormone is the signal to affect oviduct epithelial cells to release spermatozoa. There have been reports to suggest that progesterone plays an important role in capacitation, inducing acrosome reaction (Katayama et al., 2002).

Progesterone has also been identified as a hormone of pregnant mammals. Many structural and functional changes of the reproductive tract during pregnancy have been ascribed to progesterone. The present study was undertaken with the objectives of investigating if progesterone improves the commonly used porcine oocyte maturation and culture medium under the conditions of in vitro fertilisation.

\section{Materials and methods}

Unless stated otherwise, all chemicals were obtained from Sigma-Aldrich Chemicals (Alcohobendas, Madrid, Spain). The medium used for the collection and washing of cumulus-oocyte complexes (COCs) was Dulbecco's phosphate buffered saline medium (DPBSm) composed of $136.89 \mathrm{mM} \mathrm{NaCl}, 2.68 \mathrm{mM} \mathrm{KCl}$, $8.1 \mathrm{mM} \mathrm{Na}_{2} \mathrm{HPO}_{4}$ and $1.46 \mathrm{mM} \mathrm{CaCl}_{2} \times 2 \mathrm{H}_{2} \mathrm{O}, 0.34 \mathrm{mM}$ sodium pyruvate, $5.4 \mathrm{mM}$ glucose and $70 \mu \mathrm{g} / \mathrm{ml}$ kanamycin, adding $4 \mathrm{mg} / \mathrm{ml}$ bovine serum albumin (BSA; fraction V) just before use. The basic medium used for oocyte maturation was a modified North Caroline State University (NCSU)-23 supplemented with 10\% $(\mathrm{v} / \mathrm{v})$ porcine follicular fluid, $0.8 \mathrm{mM}$ cysteine and $10 \mathrm{ng} / \mathrm{ml}$ epidermal growth factor (EGF). The fertilisation medium was a modified Tris-buffered medium (mTMB) consisting of $113.1 \mathrm{mM} \mathrm{NaCl}, 3 \mathrm{mM} \mathrm{KCl}, 7.5 \mathrm{mM} \mathrm{CaCl} \times 2 \mathrm{H}_{2} \mathrm{O}$, $20 \mathrm{mM}$ Tris, $11 \mathrm{mM}$ glucose and $5 \mathrm{mM}$ sodium pyruvate, supplemented with $2 \mathrm{mM}$ caffeine and $0.2 \%$ BSA. The embryo culture medium was glucose-free NCSU-23 supplemented with sodium lactate, pyruvic acid and $0.4 \%$ BSA.

\section{Oocyte collection and in vitro maturation}

Ovaries of prepuberal gilts were collected at a slaughterhouse and transported to the laboratory in DPBSm at $33{ }^{\circ} \mathrm{C}$. COCs were collected from follicles 2-6 $\mathrm{mm}$ in diameter. They were washed and matured for $22 \mathrm{~h}$ in $500 \mu 1$ matura- 
tion medium supplemented with $10 \mathrm{IU} / \mathrm{ml}$ of eCG and $10 \mathrm{IU} / \mathrm{ml}$ of hCG at $39{ }^{\circ} \mathrm{C}$ in an atmosphere of 5\% $\mathrm{CO}_{2}$ in air and $70 \%$ humidity. As the second step, they were subsequently cultured for $22 \mathrm{~h}$ in the chorionic gonadotropin free maturation medium, supplemented with 0 or $10 \mathrm{IU} / \mathrm{ml}$ of progestagens (Sinestro Neosan ${ }^{\circledR}$, Pfizer, Spain). After maturation, oocytes were collected and the surrounding cumulus cells were removed by vortex in $0.1 \%$ hyaluronidase for 2 min. Matured oocytes were washed in fertilisation medium. Groups of 30 oocytes were placed into $50 \mu \mathrm{l}$ droplets of the same medium for about $30 \mathrm{~min}$ until addition of spermatozoa. Resting oocytes were fixed after $48 \mathrm{~h}$ of maturation to determine nuclear maturation.

\section{In vitro fertilisation and culture}

For fertilisation, straws of ejaculated semen, previously cryopreserved using an adapted Westendorf et al. (1975) method as modified (Carvajal et al., 2004), were thawed at $37^{\circ} \mathrm{C}$ for $21 \mathrm{sec}$ and then resuspended in BTS $\left(1: 4, \mathrm{v} / \mathrm{v} ; 37^{\circ} \mathrm{C}\right)$. One hundred $\mu$ of thawed semen were washed by centrifugation at $1900 \times g$ for $3 \mathrm{~min}$ in mDPBS. The pellet was resuspended in fertilisation medium and sperm concentration was adjusted to produce a final optimum ratio of 2000:1 spermatozoa/oocyte previously demonstrated for boars used in the experiments. Sperm and oocytes were co-incubated at $39^{\circ} \mathrm{C}$ under $5 \% \mathrm{CO}_{2}$ in air for $6 \mathrm{~h}$. Presumptive zygotes were removed from the fertilisation medium, washed three times in embryo culture medium and then transferred to a $500 \mu 1$ drop of the same medium under mineral oil, and cultured at $39{ }^{\circ} \mathrm{C}$ in $5 \% \mathrm{CO}_{2}$ in air for $16-18 \mathrm{~h}$ to evaluate the fertilisation parameters.

\section{Assessment of in vitro fertilisation}

To evaluate in vitro fertilisation, presumptive zygotes and resting oocytes were then fixed for at least $72 \mathrm{~h}$ in slide fixing solution (1:3; acetic acid : ethanol) and then stained with Lacmoid (1\%). Pre-maturation rate (oocytes in MII after $44 \mathrm{~h}$ maturation/total inseminated), penetration rate (presence of female pronucleus and one or more swollen sperm heads and/or male pronuclei with their corresponding head and two polar bodies/matured inseminated), monospermy rates (oocytes containing only one sperm head or male pronuclei/total penetrated) and efficiency of fertilisation (monospermic oocytes/total inseminated) were measured. Nuclear maturation was measured in resting oocytes.

\section{Experimental design}

In this experiment, the effects of progestagens on in vitro late maturation and fertilisation were examined in different in vitro systems. Control oocytes were matured with PMSG (eCG) and hCG for $22 \mathrm{~h}$ and subsequently matured without hormones for $22 \mathrm{~h}$. After fertilisation, presumptive zygotes were cultured 
in hormone-free media for 16-20 h. Oocytes from the test group were matured with PMSG and hCG for $22 \mathrm{~h}$ and subsequently matured with progestagens for $22 \mathrm{~h}$. After fertilisation, presumptive zygotes were cultured in media supplemented with progestagens for 16-20 h. A total of 1421 oocytes from four replicates were used.

\section{Statistical analysis}

All analyses were performed using SPSS 15.0 for Windows. Percentage data were assessed using Pearson's chi-squared test. Differences were considered significant at $\mathrm{P}<0.05$.

\section{Results}

Effects of progestagens added to late maturation and culture media on fertility parameters

As shown in Table 1, the pre-maturation percentages (after a 44-h maturation period) did not differ significantly between the two groups. However, sperm penetration per oocyte was significantly higher $(\mathrm{P}<0.001)$ in progestagencultured oocytes $(75 \%)$ as compared in monospermy $(\mathrm{P}=0.246)$. The addition of progestagens remarkably increased the efficiency of the IVF system $(\mathrm{P}<0.001)$.

Table 1

Effect of progestagen supplementation during in vitro late maturation of porcine cumulus-oocyte complexes (COCs) and embryo culture on fertility parameters

\begin{tabular}{lccccc}
\hline Treatment & $\begin{array}{c}\text { Number } \\
\text { of oocytes }\end{array}$ & $\begin{array}{c}\text { Pre-maturation } \\
(\%)\end{array}$ & $\begin{array}{c}\text { Penetration } \\
(\%)\end{array}$ & $\begin{array}{c}\text { Monospermy } \\
(\%)\end{array}$ & $\begin{array}{c}\text { Efficiency } \\
(\%)\end{array}$ \\
\hline Control & 583 & 78.6 & $51.7^{\mathrm{a}}$ & 87.8 & $35.7^{\mathrm{a}}$ \\
Progestagens & 636 & 80.5 & $75.0^{\mathrm{b}}$ & 89.9 & $51.7^{\mathrm{b}}$ \\
\hline P value & & 0.221 & $<0.001$ & 0.246 & $<0.001$ \\
\hline
\end{tabular}

${ }^{\mathrm{a}, \mathrm{b}}$ Values with different superscript letters within a column differ significantly $(\mathrm{P}<0.05)$

\section{Effects of progestagens added to late maturation media on nuclear maturation}

The rates of nuclear maturation of porcine oocytes after a 48-h maturation period are summarised in Table 2 . The metaphase II formation was significantly $(\mathrm{P}<0.035)$ higher in COCs that were matured in the presence of progestagens during the late maturation period (last $22 \mathrm{~h}$ ) compared with the control COCs without progestagens ( $72.1 \%$ vs. $58.8 \%$, respectively). 
Table 2

Effects of progestagen supplementation during in vitro late maturation of porcine cumulus-oocyte complexes (COCs) on maturation rates

\begin{tabular}{lcc}
\hline Treatment & Number of oocytes & Maturation $(\%)$ \\
\hline Control & 80 & $58.8^{\mathrm{a}}$ \\
Progestagens & 122 & $72.1^{\mathrm{b}}$ \\
\hline P value & 0.035 \\
\hline a, b Values with different superscript letters within a column \\
differ significantly $(\mathrm{P}<0.05)$
\end{tabular}

\section{Discussion}

In vitro production of porcine embryos by IVF is still inefficient compared with in vivo produced embryos (Abeydeera et al., 1998). This inefficiency is due to various causes such as a high rate of polyspermy and a low quality of blastocysts. The main factors affecting the yield and quality of pig blastocysts obtained in vitro are the culture conditions. The production of sex steroids by follicular cells is proposed to be influenced by the maturity of oocytes. The study demonstrated that progesterone had a marked effect on maturation and fertilisation in vitro. Supplementation of late maturation and culture media with 10 IU of progesterone enhanced penetration and efficiency of the IVF system. In addition, progesterone increased MII formation.

Several reports have investigated improving two commonly used porcine embryo culture media, NCSU-23 and 37 (Raychoudhury and Suárez, 1991; Kikuchi et al., 2002; Karja et al., 2004; Beebe et al., 2009). Very few experiments have studied the use of hormones in the maturation of porcine oocytes (Eroglu, 1993; Bing et al., 2001; Dode and Graves, 2002). The addition of a suitable hormone supplement to maturation media enhances nuclear maturation and cumulus expansion (Minato and Toyoda, 1982). However, subsequent studies demonstrated that the removal of hormones improved cytoplasm maturation (Funahashi and Day, 1993).

Dode and Graves (2002) have indicated that no sexual steroids need to be added to the maturation medium of pig oocytes because COCs secrete steroids during maturation. Moreover, the addition of steroids reduced the proportion of oocytes that reached MII (Singh et al., 1993; Bing et al., 2001). However, Kim et al. (2011) observed a positive effect of oestrogens on oocyte maturation and early embryo culture during the first half of the IVM period. Funahashi and Day (1993) demonstrated that $20 \mathrm{~h}$ of maturation with no hormone supplementation would be necessary to improve cytoplasmic maturation. Based on the regulated 
sequence of hormonal changes during in vivo maturation, some reports established a two-step IVM system consisting of 22-h incubation with hCG and eCG followed by 22-h incubation with hormone-free media (Marques et al., 2007; Gil et al., 2010).

The discovery of the inhibitory effects of oestrogens by the addition of progesterone in previous reports ( $\mathrm{Li}$ et al., 2004) was the basis of the present study. Progesterone is required for the maturation of rat (Zhang and Armstrong, 1989) and pig (Shimada and Terada, 2002) oocytes. In porcine (Eroglu, 1993) and bovine (Sirotkin, 1992) oocytes, the addition of progesterone to a maturation medium stimulated meiotic resumption. Our results are also consistent with these findings. The competence of monospermic fertility is dependent on the degree of cytoplasmic maturation in MII oocytes (Han et al., 1990). In the present study, the incidence of polyspermic penetration was very low in both groups. The mechanism of action of progesterone is not clear at present. Hunter (1991) hypothesised that progesterone may modify the interaction of gametes. Furthermore, progesterone reduces the expression of connexin 43, a gap protein, in the outer layer of cumulus cells, resulting in meiotic resumption (Shimada and Terada, 2002). In a previous study, Shimada and Terada (2001) demonstrated that the total amount of connexin 43 in cumulus cells was reduced after $12 \mathrm{~h}$ of culture, concomitantly with the activation of meiosis. In conformity with our results, Katayama et al. (2002) showed that progesterone induced acrosome reaction, promoting male pronucleus formation. Although progesterone is produced in media in which COCs were cultured with LH and FSH, supplementation in the last period of maturation improved penetration and the total efficiency of IVF. In contrast, recently Larson et al. (2011) have confirmed that the use of progesterone during the culture of in vitro produced embryos does not improve embryo characteristics.

In conclusion, the addition of progesterone to late maturation and culture media caused an improvement in maturation and an increase in penetration and efficiency of the IVF system. These results showed that a high level of progesterone is involved in the cytoplasmic maturation of porcine embryos.

\section{Acknowledgements}

This study was supported by the EUROAGRI + PROVISEM project. We thank The Pink Pig S. A. (Zuera) for providing swine oocytes. 


\section{References}

Abeydeera, L. R., Wang, W. H., Prather, R. S. and Day, B. N. (1998): Maturation in vitro of pig oocytes in protein-free culture media: Fertilization and subsequent embryo development in vitro. Biol. Reprod. 58, 1316-1320.

Beebe, L. F., Vassiliev, I., McIlfatrick, S. and Nottle, M. B. (2009): Adding essential amino acids at a low concentration improves the development of in vitro fertilized porcine embryos. J. Reprod. Dev. 55, 373-377.

Bing, Y. Z., Nagai, T. and Rodriguez-Martinez, H. (2001): Effects of cysteamine, FSH and estradiol-17beta on in vitro maturation of porcine oocytes. Theriogenology 55, 867-876.

Carvajal, G., Cuello, C., Ruiz, M., Vazquez, J. M., Martinez, E. A. and Roca, J. (2004): Effects of centrifugation before freezing on boar sperm cryosurvival. J. Androl. 25, 389-396.

Dode, M. A. and Graves, C. (2002): Involvement of steroid hormones on in vitro maturation of pig oocytes. Theriogenology 57, 811-821.

Eroglu, A. (1993): Experimental studies on in vitro maturation of porcine oocytes. II. Effects of estradiol-17 beta and progesterone. Berl. Münch. Tierärztl. Wochenschr. 106, 157-159.

Faerge, I., Strejcek, F., Laurincik, J., Rath, D., Niemann, H., Schellander, K., Rosenkranz, C., Hyttel, P. M. and Grondahl, C. (2006): The effect of FF-MAS on porcine cumulus-oocyte complex maturation, fertilization and pronucleus formation in vitro. Zygote 14, 189-199.

Funahashi, H. (2003): Polyspermic penetration in porcine IVM-IVF systems. Reprod. Fertil. Dev. 15, $167-177$.

Funahashi, H. and Day, B. N. (1993): Effects of the duration of exposure to hormone supplements on cytoplasmic maturation of pig oocytes in vitro. J. Reprod. Fertil. 98, 179-185.

Funahashi, H., Cantley, T. and Day, B. N. (1994): Different hormonal requirements of pig oocytecumulus complexes during maturation in vitro. J. Reprod. Fertil. 101, 159-165.

Gil, M. A., Cuello, C., Parrilla, I., Vazquez, J. M., Roca, J. and Martinez, E. A. (2010): Advances in swine in vitro embryo production technologies. Reprod. Domest. Anim. 45, Suppl. 2, $40-48$

Han, Y. M., Abeydeera, L. R., Kim, J. H., Moon, H. B., Cabot, R. A., Day, B. N. and Prather, R. S. (1990): Growth retardation of inner cell mass cells in polyspermic porcine embryos produced in vitro. Biol. Reprod. 60, 1110-1113.

Hunter, M. G., Southee, J. A. and Lamming, G. E. (1988): Function of abnormal corpora lutea in vitro after GnRH-induced ovulation in the anoestrous ewe. J. Reprod. Fertil. 84, 139-148.

Hunter, R. H. (1991): Oviduct function in pigs, with particular reference to the pathological condition of polyspermy. Mol. Reprod. Dev. 29, 385-391.

Karja, N. W., Medvedev, S., Onishi, A., Fuchimoto, D., Iwamoto, M., Otoi, T. and Nagai, T. (2004): Effect of replacement of pyruvate/lactate in culture medium with glucose on preimplantation development of porcine embryos in vitro. J. Reprod. Dev. 50, 587-592.

Katayama, M., Miyano, T., Miyake, M. and Kato, S. (2002): Progesterone treatment of boar spermatozoa improves male pronuclear formation after intracytoplasmic sperm injection into porcine oocytes. Zygote 10, 95-104.

Kikuchi, K., Onishi, A., Kashiwazaki, N., Iwamoto, M., Noguchi, J., Kaneko, H., Akita, T. and Nagai, T. (2002): Successful piglet production after transfer of blastocysts produced by a modified in vitro system. Biol. Reprod. 66, 1033-1041.

Kim, J. S., Song, B. S., Lee, S. R., Yoon, S. B., Huh, J. W., Kim, S. U., Kim, E., Kim, S. H., Choo, Y. K., Koo, D. B. and Chang, K. T. (2011): Supplementation with estradiol-17beta improves porcine oocyte maturation and subsequent embryo development. Fertil. Steril. 95, 2582-2584.

Larson, J. E., Krisher, R. L. and Lamb, G. C. (2011): Effects of supplemental progesterone on the development, metabolism and blastocyst cell number of bovine embryos produced in vitro. Reprod. Fertil. Dev. 23, 311-318. 
Li, Q., Niwa, K. and Hunter, M. G. (2004): Effects of 17beta-estradiol on in vitro maturation of pig oocytes in protein-free medium. J. Reprod. Dev. 50, 305-313.

Marchal, R., Tomanek, M., Terqui, M. and Mermillod, P. (2001): Effects of cell cycle dependent kinases inhibitor on nuclear and cytoplasmic maturation of porcine oocytes. Mol. Reprod. Dev. 60, 65-73.

Marques, M. G., Nicacio, A. C., de Oliveira, V. P., Nascimento, A. B., Caetano, H. V., Mendes, C. M., Mello, M. R., Milazzotto, M. P., Assumpcao, M. E. and Visintin, J. A. (2007): In vitro maturation of pig oocytes with different media, hormone and meiosis inhibitors. Anim. Reprod. Sci. 97, 375-381.

Minato, Y. and Toyoda, Y. (1982): Induction of cumulus expansion and maturation division of porcine oocyte-cumulus complexes in vitro. Jpn. J. Zootech. Sci. 53, 480-487.

Niwa, K. (1994): Effectiveness of in vitro maturation and in vitro fertilization techniques in pigs. J. Reprod. Fertil. Suppl. 48, 49-59.

Peters, R. M. and Wells, K. D. (1994): Culture of pig embryos. J. Reprod. Fertil. 48, 61-73.

Raychoudhury, S. S. and Suárez, S. (1991): Porcine sperm binding to oviductal explants in culture. Theriogenology 36, 1059-1070.

Raziel, A., Schachter, M., Strassburger, D., Kasterstein, E., Ron-El, R. and Friedler, S. (2006): In vivo maturation of oocytes by extending the interval between human chorionic gonadotropin administration and oocyte retrieval. Fertil. Steril. 86, 583-587.

Shimada, M. and Terada, T. (2001): Phosphatidylinositol 3-kinase in cumulus cells and oocytes is responsible for activation of oocyte mitogen-activated protein kinase during meiotic progression beyond the meiosis I stage in pigs. Biol. Reprod. 64, 1106-1114.

Shimada, M. and Terada, T. (2002): FSH and LH induce progesterone production and progesterone receptor synthesis in cumulus cells: A requirement for meiotic resumption in porcine oocytes. Mol. Hum. Reprod. 8, 612-618.

Silvestre, M. A., Alfonso, J., Garcia-Mengual, E., Salvador, I., Duque, C. C. and Molina, I. (2007): Effect of recombinant human follicle-stimulating hormone and luteinizing hormone on in vitro maturation of porcine oocytes evaluated by the subsequent in vitro development of embryos obtained by in vitro fertilization, intracytoplasmic sperm injection, or parthenogenetic activation. J. Anim. Sci. 85, 1156-1160.

Singh, B., Barbe, G. J. and Armstrong, D. T. (1993): Factors influencing resumption of meiotic maturation and cumulus expansion of porcine oocyte-cumulus cell complexes in vitro. Mol. Reprod. Dev. 36, 113-119.

Sirard, M. A., Richard, F., Blondin, P. and Robert, C. (2006): Contribution of the oocyte to embryo quality. Theriogenology 65, 126-136.

Sirotkin, A. V. (1992): Involvement of steroid hormones in bovine oocytes maturation in vitro. J. Steroid Biochem. Mol. Biol. 41, 855-858.

Wang, W. and Niwa, K. (1995): Synergetic effects of epidermal growth factor and gonadotropins on the cytoplasmic maturation of pig oocytes in a serum-free medium. Zygote 3, 345-350.

Wen, X., Tozer, A. J., Li, D., Docherty, S. M., Al-Shawaf, T. and Iles, R. K. (2008): Human granulosa-lutein cell in vitro production of progesterone, inhibin A, inhibin B, and activin A are dependent on follicular size and not the presence of the oocyte. Fertil. Steril. 89, Suppl. 5, $1406-1413$.

Westendorf, P., Richter, L. and Treu, H. (1975): Deep freezing of boar sperm: laboratory and insemination results using the Hulsenberger paillete method. Dtsch. Tierärztl. Wochenschr. 82, 261-267.

Zhang, X. and Armstrong, D. T. (1989): Effects of follicle-stimulating hormone and ovarian steroids during in vitro meiotic maturation on fertilization of rat oocytes. Gamete Res. 23, 267-277. 